\title{
Ximenynic Acid Regulation of n-3 PUFA Content in Liver and Brain
}

\author{
Fang Cai ${ }^{\mathrm{a}-\mathrm{c}}$ Yandi Liu ${ }^{\mathrm{d}}$ Dhanushka S. Hettiarachichid ${ }^{\mathrm{F}}$ Fenglei Wang ${ }^{\mathrm{c}} \quad \mathrm{Jie} \mathrm{Li}^{\mathrm{c}}$ \\ Bruce Sunderland ${ }^{d}$ Duo Li ${ }^{\mathrm{a}, \mathrm{c}}$ \\ anstitute of Nutrition and Health, Qingdao University, Qingdao, China; \\ b'Institute of Plant Genetics and Breeding, School of Life Sciences, Guizhou Normal University, Guiyang, China; \\ 'Department of Food Science and Nutrition, Zhejiang University, Hangzhou, China; \\ ${ }^{\mathrm{d}}$ School of Pharmacy, Curtin Health Innovation Research Institute, Curtin University, Perth, WA, Australia
}

\section{Keywords}

Ximenynic acid · Sandalwood seed oil .

Fatty acid metabolism - Fatty acid desaturase .

Stearoyl-CoA desaturase

\begin{abstract}
Background/Aims: Ximenynic acid is a rare conjugated enyne fatty acid found primarily in plants in the Santalaceae family. It has been reported that sandalwood seed oil (SWSO) affects fatty acid metabolism in animal studies; however, the effects of pure ximenynic acid remain unclear. The present study aimed to study the impact of SWSO and ximenynic acid on n-3 fatty acid metabolism in the liver and brain. Methods: Thirty C57BL/6 male mice aged 4 weeks were fed SWSO (1.0 mL/20 g bodyweight), olive oil (OO), or a combination of SWSO and OO ( $n=10 /$ group) for 8 weeks. Liver and brain fatty acid compositions were determined using gas chromatography. HepG2 cells were treated with up to 150 $\mu \mathrm{M}$ ximenynic acid and oleic acid for 48-72 h. The expression and abundance of genes and proteins relevant to $n-3$ fatty acid metabolism pathways were investigated. Results: The intake of SWSO in mice elevated the levels of total n-3 fatty acids and decreased total n-9 fatty acids in the liver $(p<0.05)$ compared with the OO group. In contrast, total
\end{abstract}

\begin{tabular}{ll}
\hline KARGER & ( ) 2020 The Author(s) Karger \\
& Published by S. Karger AG, Basel Open access \\
karger@karger.com & This article is licensed under the Creative Commons Attribution- \\
NonCommercial-NoDerivatives 4.0 International License (CC BY- & NC-ND) (http://www.karger.com/Services/OpenAccessLicense). \\
Usage and distribution for commercial purposes as well as any dis- \\
tribution of modified material requires written permission.
\end{tabular}

$\mathrm{n}-3$ fatty acids were significantly decreased in the brain $(p<0.05)$. HepG2 cells treated with ximenynic acid for $48 \mathrm{~h}$ showed significant reductions in $n-9$ fatty acids and docosahexaenoic acid (C22:6n-3) $(p<0.05)$ compared with HepG2 cells treated with oleic acid. In HepG2 cells, stearoyl-CoA desaturase (SCD) and fatty acid desaturase 2 (FADS2) gene expression, as well as FADS2 protein expression, were significantly down-regulated after a 72-h incubation with $150 \mu \mathrm{M}$ of ximenynic acid compared with the vehicle $(p<0.05)$. Conclusion: Ximenynic acid may regulate fatty acid metabolism by suppressing the expression of key enzymes of lipid metabolism. In contrast, SWSO, which has a high level of C18:3n-3, positively affected $n-3$ fatty acid synthesis in mouse liver compared to pure ximenynic acid. We hypothesize that a high level of precursor C18:3n-3 in SWSO promotes the endogenous synthesis of $C 22: 6 n-3$ despite the presence of ximenynic acid. @ 2020 The Author(s)

Published by S. Karger AG, Basel

\section{Introduction}

Ximenynic acid [trans-11-octadecen-9-ynoic acid, $18: 2(9 \mathrm{a}, 11 \mathrm{t})]$ is a natural conjugated enyne fatty acid that is primarily found in the seed oils of plants in the Santa-
Duo Li, PhD

Institute of Nutrition and Health

Qingdao University

Qingdao 266071 (China)

duoli@qdu.edu.cn 
laceae family [1]. Sandalwood seed kernels are a valuable part of the traditional Australian aboriginal diet [2] and have been used as a topical treatment for skin lesions [3] and an oral treatment for rheumatoid arthritis [4]. The seed contains a high amount of drying fixed oil (50-60\%), which is characterized by a high percentage of unusual acetylenic fatty acids such as trans-ximenynic acid [5]. Acetylenic fatty acids have been proven to inhibit specific enzymes involved in prostaglandin synthesis and fatty acid metabolism [6-8]. Recently, acetylenic fatty acids have generated considerable interest due to their potential bioactivity as lysozyme inhibitors and their involvement in fatty acid metabolism [9].

Previous reports have displayed that the fatty acid compositions of mouse liver and adipose tissue were markedly altered following the consumption of sandalwood seed oil (SWSO) [10, 11]. Specifically, ximenynic acid metabolism was studied in mice fed a diet enriched with SWSO (15\% SWSO, 5.2\% [w/w] fat) [10]. Interestingly, mice consuming SWSO showed markedly lower levels of arachidonic acid in the liver (C20:4n-6) and higher levels of docosahexaenoic acid (C22:6n-3). Similarly, another study showed that rats consuming a diet enriched with SWSO (8\% SWSO, the fat percentage in the diet was not mentioned) had increases in total n-3 polyunsaturated fatty acids (PUFA), C22:6n-3, and the n-6: n-3 PUFA ratio [11]. Together, these previous studies suggest that ximenynic acid in SWSO may regulate n-3 fatty acid synthesis.

$a$-Linolenic acid (C18:3n-3) is an essential fatty acid that must be ingested from the diet. C18:3n-3 is the precursor fatty acid for longer-chain (20- and 22-carbon) n-3 PUFA [12]. This is relevant given that C22:6n-3 is critically essential for brain and retinal development [13]. C22:6n-3 can be obtained directly from the consumption of marine and animal food but can also be endogenously synthesized from C18:3n-3 by several desaturation and elongation reactions [14]. Fatty acid desaturase 2 (FADS2) is the rate-limiting desaturase for the synthesis of $\mathrm{C} 22$ : 6n-3 from C18:3n-3 [15]. It is demonstrated that $n-3$ PUFA can prevent and improve many chronic diseases, such as cardiovascular diseases [16], type 2 diabetes [17, 18], malignant tumors [19], Alzheimer disease [20], and inflammatory diseases [21].

The fatty acid composition of SWSO revealed that C18:1n-9 is the predominant fatty acid ( $~ 52 \%$ of total fatty acids), followed by ximenynic acid ( $\sim 31 \%$ of total fatty acids) [22], while other fatty acids were present as minor components. Differences in fatty acid profiles of SWSO have been observed; however, the variation dem-
Table 1. Composition of basic feed for mice

\begin{tabular}{ll}
\hline Nutritional constituents & Content \\
\hline Water, \% & 10 \\
Crude protein, \% & 20 \\
Crude fat, \% & 4.7 \\
Crude fiber, \% & 3.3 \\
Crude ash, \% & 6 \\
Nitrogen-free extract, \% & 54 \\
Calcium, \% & 1.1 \\
Total phosphorus, \% & 0.73 \\
Calories, kcal/100 g & 348 \\
\hline
\end{tabular}

onstrated by different authors is minimal and most likely insignificant. The goal of the present study was to investigate the effect of both SWSO and pure ximenynic acid on n-3 fatty acid metabolism using both in vivo (mice) and in vitro (HepG2) models.

\section{Materials and Methods}

\section{Reagents and Fatty Acids}

Ximenynic acid (98\%) was extracted according to a previously published method [5]. C18:1n-9 and oil-red-O solution were purchased from Sigma-Aldrich (St. Louis, MO, USA). Fatty acid methyl ester (FAME) standards were purchased from SigmaAldrich. The cDNA synthesis kit was acquired from Roche Diagnostics GmbH (Mannheim, Germany). The total RNA extraction kit was bought from Omega Bio-Tek (Norcross, GA, USA). The FADS2 antibody (CAT\#: ab72189) was purchased from Abcam Biotechnology (Cambridge, MA, USA), and GAPDH antibody (CAT\#: 2118s) and anti-rabbit IgG, HRP-linked antibody (CAT\#: 7074) were purchased from Cell Signaling Technology (Danvers, MA, USA). SsoFast ${ }^{\mathrm{TM}}$ EvaGreen ${ }^{\circledR}$ Supermix was purchased from Bio-Rad Laboratories (Hercules, CA, USA). All reagents were of analytical or HPLC grade.

\section{Animals and Diets}

Four-week-old C57BL/6 male mice were obtained from the Laboratory Animal Center, Zhejiang University (Hangzhou, China). Mice were housed in a specific pathogen-free animal laboratory under constant temperature and humidity, and with a 12-h dark:12-h light cycle. Mice had ad libitum access to water and a basic feed (SLaCCaS, Shanghai, China), which was comprised of $57.3 \%$ carbohydrates, $20 \%$ proteins, and $4.7 \%$ fat (Table 1 ). After 7 days of adaptation to the basic feed, mice were divided into 3 groups ( $n=10$ /group): olive oil (OO), SWSO, or a 1:1 mixture of OO and SWSO (SO). Because SWSO contains a high amount of ximenynic acid, which is highly oxidizable, oils were administered by oral gavage ( $1 \mathrm{~mL} / 20 \mathrm{~g}$ body weight) once every 2 days for 8 weeks. This ensured that we could control the energy and fat intake of mice. At the end of the 8-week feeding period, mice were fasted overnight and then sacrificed after anesthesia (10\% chloral hy- 
drate). Tissue samples were collected from anesthetized mice and stored at $-80^{\circ} \mathrm{C}$ until analysis.

\section{Cell Culture}

The human liver HepG2 cell line was available from the Type Culture Collection of the Chinese Academy of Sciences (TCCCAS, Shanghai, China). Cells were cultured in complete culture medium that was changed every 2 days until cells reached $80 \%$ confluence. Cells were serum starved for $24 \mathrm{~h}$ with fatty acid-free media prior to treatment with several different concentrations of ximenynic acid or C18:1n-9 (0-150 $\mu \mathrm{M})$ for 48-72 h. The fatty acids used for in vitro treatments were first dissolved in DMSO, then in fatty acid-free bovine serum albumin (BSA) with a molar ratio of $4: 1$, and later dissolved in fatty acid-free medium. We previously ran a toxicity test [8] and found that the $\mathrm{IC}_{50}$ for ximenynic acid in HepG 2 cells was about $194.2 \mu \mathrm{M}$ after $72 \mathrm{~h}$. Therefore, the concentrations employed in the present study were deemed nontoxic.

Complete culture medium was composed of Dulbecco's modified Eagle's medium (DMEM; Invitrogen, CA, USA), 10\% fetal bovine serum (FBS; Biowest, Nuaille, France), antibiotics (100 U/mL penicillin and $100 \mu \mathrm{g} / \mathrm{mL}$ streptomycin), $0.11 \mathrm{~g} / \mathrm{L}$ sodium pyruvate, $4 \mathrm{mM}$ L-glutamine, and $10 \mathrm{~mm}$ HEPES (Corning Inc., New York, NY, USA). Fatty acid-free medium contained 1\% insulintransferrin-selenium (Invitrogen, CA, USA), $100 \mathrm{mg} / \mathrm{mL}$ fatty acid-free BSA (MP Biomedicals, CA, USA), antibiotics (100 U/mL penicillin and $100 \mu \mathrm{g} / \mathrm{mL}$ streptomycin), $0.11 \mathrm{~g} / \mathrm{L}$ sodium pyruvate, $4 \mathrm{mM}$ L-glutamine, and $10 \mathrm{mM}$ HEPES (Corning Inc.). The vehicle medium was fatty acid-free medium supplemented with DMSO and BSA with the same concentration of the experimental medium.

\section{Oil-Red-O Staining}

Cells were seeded in 24-well plates with 20,000 cells/well and incubated overnight. The next day, the cell monolayer was washed with phosphate-buffered saline (PBS) and treated with fatty acids. After incubation for $48 \mathrm{~h}$, cells were gently washed with PBS and fixed with $10 \%$ formaldehyde for $30 \mathrm{~min}$. Cells were gently rinsed again to eliminate formaldehyde and stained with oil-red-O working solution for $30 \mathrm{~min}$. Excess oil-red-O solution was removed by sequential rinses in PBS. Images were acquired by an inverted microscope (Olympus, Tokyo, Japan).

\section{Fatty Acid Composition Analysis}

Cells were washed twice with ice-cold PBS, scraped on ice into a glass tube, and then centrifuged $\left(2,000 \mathrm{rpm}, 10 \mathrm{~min}, 4^{\circ} \mathrm{C}\right)$. After removing the supernatant, $5 \mathrm{~mL}$ of a chloroform-methanol $(2: 1 \mathrm{v} / \mathrm{v})$ solution containing $0.005 \%$ butylated hydroxyl toluene (BHT) was added. The solution was vortexed vigorously and then kept at $-20^{\circ} \mathrm{C}$ for $24 \mathrm{~h}$. The solution was filtered into a new glass tube and then dried under nitrogen in a $50{ }^{\circ} \mathrm{C}$ water bath. Next, $4 \mathrm{~mL}$ of sulfuric acid in methanol $(0.9 \mathrm{~mol} / \mathrm{L})$ and $1 \mathrm{~mL}$ methylbenzene were added, and the samples were methylated at $70{ }^{\circ} \mathrm{C}$ for $2 \mathrm{~h}$. Subsequently, $2 \mathrm{~mL}$ hexane and $1 \mathrm{~mL}$ saline were added to each sample prior to centrifugation $(2,000 \mathrm{rpm}, 10 \mathrm{~min}$, $4{ }^{\circ} \mathrm{C}$ ); the upper phase was removed, placed in a new glass tube, and then washed with distilled water and dried with anhydrous sodium sulfate. FAME derivatives were purified with a Supelclean $^{\mathrm{TM}}$ LC-Si SPE Tube (Sigma-Aldrich). The FAME cleaning solution was then dried under nitrogen and resuspended in 50 $\mu \mathrm{L}$ hexane.
Table 2. Primer sequences for quantitative RT-PCR

\begin{tabular}{ll}
\hline Primers & Primer sequences \\
\hline FADS1 & $\begin{array}{l}\text { Forward 5'-GCAAAGACCCAGACATCAAC-3' } \\
\text { Reverse 5'-GAAGCGGACGTAGAAGGTAATC-3' }\end{array}$ \\
\hline FADS2 & $\begin{array}{l}\text { Forward 5'-CCTTTGTCCTTGCTACCTCTC-3' } \\
\text { Reverse 5'-TCCACTTGGGTTTTCTGTAGAC-3' }\end{array}$ \\
\hline SCD & $\begin{array}{l}\text { Forward 5'-GACCTAGAAGCTGAGAAACTGG-3' } \\
\text { Reverse 5'-GCAAGAAAGTGGCAACGAAC-3' }\end{array}$ \\
\hline ELOVL2 & $\begin{array}{l}\text { Forward 5'-CTGCGGATCATGGAACATCT-3' } \\
\text { Reverse 5'-TGTTACCCAGCCATATTGAGAG-3' }\end{array}$ \\
\hline ELOVL5 & $\begin{array}{l}\text { Forward 5'-ACCCACATTTATCTGCTCTGTC-3' } \\
\text { Reverse 5'-ATTTGCCTTCCCATACTCCTG-3' }\end{array}$ \\
\hline ELOVL6 & Forward 5'-GGAAGCAGACAGGAGAACAC-3' \\
& Reverse 5'-CATACAGAGCAGAAAACAGGAAAG-3' \\
\hline RPLP0 & Forward 5'-GAAACTCTGCATTCTCGCTTC-3' \\
& Reverse 5'-GGTGTAATCCGTCTCCACAG-3' \\
\hline
\end{tabular}

RPLPO is the reference gene.

Liver and brain tissue samples (100 $\mathrm{mg}$ ) were ground on dry ice, transferred to tubes with $5 \mathrm{~mL}$ chloroform-methanol $(2: 1 \mathrm{v} / \mathrm{v})$ containing $0.005 \% \mathrm{BHT}$ and kept at $-20^{\circ} \mathrm{C}$ for $24 \mathrm{~h}$. The isolation of FAME from mouse liver and brain samples used the same protocol as that detailed above for cells.

FAME were analyzed using a GC2014 capillary GC/FID gas chromatograph (Shimadzu, Kyoto, Japan) with a DB-23 capillary column $(60 \mathrm{~m} \times 0.25 \mathrm{~mm}$ i.d., $0.25-\mu \mathrm{m}$ film thickness; Agilent Technologies, Palo Alto, CA, USA). Data were analyzed using a N2010 chromatography data system (Zhida Information Technologies, Inc., Hangzhou, China). Fatty acid data are reported as a percentage of total fatty acids.

\section{Quantitative Real-Time PCR}

Total RNA was extracted from cultured cells using the HP total RNA kit according to the manufacturer's protocol (Omega BioTek). RNA purity and concentration were determined using a NanoDrop 2000 (Thermo Scientific, Waltham, MA, USA). Next, cDNA was transcribed from $1 \mu \mathrm{g}$ total RNA by reverse transcriptase according to the manufacturer's instructions (transcriptor first-strand cDNA synthesis kit; Roche, Mannheim, Germany). Real-Time-PCR was performed using the SsoFast ${ }^{\text {TM }}$ EvaGreen ${ }^{\circledR}$ Supermix and a CFX96 ${ }^{\mathrm{TM}}$ real-time PCR detection system. Relative gene expression data were determined using Bio-Rad CFX Manager 1.5 software and the $2^{-\Delta \Delta \mathrm{C}_{\mathrm{T}}}$ method. RPLP0 was used as the housekeeping gene. Primer sequences are listed in Table 2.

\section{Western Blotting Analysis}

Cultured cells were washed twice with ice-cold PBS and scraped into a tube with cell lysis buffer containing PMSF (phenylmethanesulfonyl fluoride; Beyotime, Haimen, China) on ice. The cell protein supernatant was obtained by centrifugation $(14,000 \mathrm{rpm}$, $\left.10 \mathrm{~min}, 4^{\circ} \mathrm{C}\right)$. Protein concentration was determined with a bicin-
Cai/Liu/Hettiarachichi/Wang/Li/ Sunderland/Li 
Table 3. Fatty acid composition of experimental oils

\begin{tabular}{lrrr}
\hline Fatty acid & SWSO & \multicolumn{1}{c}{ OO } & \multicolumn{1}{c}{ SO } \\
\hline C16:0 & 3.62 & 10.04 & 7.01 \\
C18:0 & & 2.91 & 2.19 \\
C18:1n-9 & 57.82 & 79.60 & 68.76 \\
C18:2n-6 & 1.21 & 5.57 & 3.58 \\
C18:3n-3 & 4.15 & 0.61 & 2.29 \\
C20:0 & & 0.35 & 0.20 \\
C20:1n-9 & & 0.21 & 0.31 \\
C20:3n-6 & 0.23 & & \\
Ximenynic acid & 32.92 & & 15.66 \\
C22:0 & & 0.09 & \\
\hline
\end{tabular}

SWSO, sandalwood seed oil; OO, olive oil; SO, SWSO + OO.

choninic acid protein assay (Beyotime). Protein lysates $(20 \mu \mathrm{g})$ were boiled with loading buffer for $5 \mathrm{~min}$ and then separated by SDS-PAGE. Protein was transferred to PVDF (polyvinylidene difluoride) membranes and then blocked with 5\% skim milk in a PBST solution. Primary antibodies FADS2 (dilution: 1:700) and GAPDH (dilution: 1:1,000) were incubated with the above membranes for $1 \mathrm{~h}$ under agitation and then washed with PBST solution for 15 min 3 times under agitation. Following primary antibody incubation, the secondary antibody anti-rabbit IgG, HRP-linked antibody (dilution: 1:1,000) was added to the PVDF membranes for $1 \mathrm{~h}$ and washed with PBST solution as above. Immunoreactive bands were detected by electrochemiluminescent detection reagent, and the data were analyzed with Quantity One software (Bio-Rad).

\section{Statistical Analysis}

Data were analyzed using independent-sample $t$ tests or oneway analysis of variance (ANOVA) using SPSS 22.0 (SPSS Inc., Chicago, IL, USA). Data are presented as means \pm SD. A value of $p<0.05$ was regarded as statistically significant.

\section{Results}

\section{Effects of SWSO on Mouse Hepatic Fatty Acid}

\section{Composition}

SWSO (Santalum spicatum R.Br.) contains high levels of C18:1n-9 ( 58\%) and ximenynic acid ( 33\%). Consequently, we chose to use $\mathrm{OO}(\sim 80 \% \mathrm{C} 18: 1 \mathrm{n}-9)$ as the control oil. The SO treatment consisted of homogeneous mixture of an equal amount of SWSO and OO. The fatty acid compositions of the experimental oils are shown in Table 3.

There were no significant differences in individual saturated fatty acids (SFA) or total SFA in the livers between any of the experimental groups (Table 4). Intriguingly,
Table 4. Effects of different oil feeds on total fatty acid composition in mouse liver

\begin{tabular}{|c|c|c|c|}
\hline Fatty acid & $\mathrm{OO}$ & $\mathrm{SO}$ & SWSO \\
\hline C14:0 & $0.21 \pm 0.05^{\mathrm{a}}$ & $0.2 \pm 0.09^{\mathrm{a}}$ & $0.17 \pm 0.03^{\mathrm{a}}$ \\
\hline C15:0 & $0.16 \pm 0.04^{\mathrm{a}}$ & $0.19 \pm 0.12^{\mathrm{a}}$ & $0.1 \pm 0.09^{\mathrm{a}}$ \\
\hline C16:0 & $18.44 \pm 1.46^{\mathrm{a}}$ & $17.83 \pm 1.19^{\mathrm{a}}$ & $19.14 \pm 1.45^{\mathrm{a}}$ \\
\hline C17:0 & $0.17 \pm 0.03^{\mathrm{a}}$ & $0.17 \pm 0.04^{\mathrm{a}}$ & $0.19 \pm 0.03^{\mathrm{a}}$ \\
\hline C18:0 & $5.44 \pm 1.12^{\mathrm{a}}$ & $5.28 \pm 0.76^{\mathrm{a}}$ & $5.32 \pm 1.04^{\mathrm{a}}$ \\
\hline C20:0 & $0.08 \pm 0.07^{\mathrm{a}}$ & $0.08 \pm 0.06^{\mathrm{a}}$ & $0.06 \pm 0.09^{\mathrm{a}}$ \\
\hline C22:0 & $0.15 \pm 0.03^{\mathrm{a}}$ & $0.17 \pm 0.03^{\mathrm{a}}$ & $0.16 \pm 0.05^{\mathrm{a}}$ \\
\hline C24:0 & $0.14 \pm 0.05^{\mathrm{a}}$ & $0.13 \pm 0.06^{\mathrm{a}}$ & $0.17 \pm 0.15^{\mathrm{a}}$ \\
\hline Total SFA & $24.8 \pm 2.63^{\mathrm{a}}$ & $24.05 \pm 1.88^{\mathrm{a}}$ & $25.31 \pm 2.41^{\mathrm{a}}$ \\
\hline C16:1n-7 & $1.05 \pm 0.21^{\mathrm{b}}$ & $1.37 \pm 0.26^{\mathrm{a}}$ & $1.62 \pm 0.33^{\mathrm{a}}$ \\
\hline $\mathrm{C} 17: 1 \mathrm{n}-7$ & $0.48 \pm 0.2^{\mathrm{a}}$ & $0.78 \pm 0.51^{\mathrm{a}}$ & $0.15 \pm 0.03^{b}$ \\
\hline C18:1n-9 & $21.82 \pm 2.23^{\mathrm{a}}$ & $20.99 \pm 3.01^{\mathrm{ab}}$ & $18.76 \pm 1.68^{b}$ \\
\hline C20:1n-9 & $0.27 \pm 0.05^{\mathrm{a}}$ & $0.25 \pm 0.03^{\mathrm{a}}$ & $0.24 \pm 0.02^{\mathrm{a}}$ \\
\hline C22:1n-9 & $1.11 \pm 0.4^{\mathrm{a}}$ & $1.03 \pm 0.36^{\mathrm{a}}$ & $1.26 \pm 0.39^{\mathrm{a}}$ \\
\hline C24:1n-9 & $0.28 \pm 0.06^{\mathrm{a}}$ & $0.25 \pm 0.08^{\mathrm{a}}$ & $0.23 \pm 0.11^{\mathrm{a}}$ \\
\hline Total n-9 MUFA & $23.45 \pm 1.94^{\mathrm{a}}$ & $22.53 \pm 2.81^{\mathrm{a}, \mathrm{b}}$ & $20.52 \pm 1.44^{\mathrm{b}}$ \\
\hline Total MUFA & $24.97 \pm 2.06^{\mathrm{a}}$ & $24.67 \pm 2.94^{\mathrm{a}}$ & $22.29 \pm 1.65^{\mathrm{b}}$ \\
\hline C18:2n-6 & $26.26 \pm 1.8^{\mathrm{a}}$ & $25.67 \pm 1.93^{\mathrm{a}}$ & $25.11 \pm 1.99^{a}$ \\
\hline$C 18: 3 n-6$ & $0.43 \pm 0.12^{\mathrm{a}, \mathrm{b}}$ & $0.44 \pm 0.08^{\mathrm{a}}$ & $0.34 \pm 0.07^{\mathrm{b}}$ \\
\hline C20:2n-6 & $0.15 \pm 0.06^{\mathrm{b}}$ & $0.16 \pm 0.03^{\mathrm{b}}$ & $0.23 \pm 0.04^{\mathrm{a}}$ \\
\hline$C 20: 3 n-6$ & $0.74 \pm 0.11^{\mathrm{c}}$ & $1.08 \pm 0.21^{\mathrm{b}}$ & $1.39 \pm 0.23^{\mathrm{a}}$ \\
\hline$C 20: 4 n-6$ & $8.26 \pm 0.89^{\mathrm{a}}$ & $7.98 \pm 1.39^{\mathrm{a}}$ & $8.26 \pm 1.17^{\mathrm{a}}$ \\
\hline$C 22: 4 n-6$ & $0.15 \pm 0.08^{\mathrm{a}}$ & $0.11 \pm 0.03^{\mathrm{b}}$ & $0.09 \pm 0.02^{\mathrm{b}}$ \\
\hline Total n-6 PUFA & $35.99 \pm 1.02^{\mathrm{a}}$ & $35.43 \pm 1.61^{\mathrm{a}}$ & $35.41 \pm 1.24^{\mathrm{a}}$ \\
\hline C18:3n-3 & $1.03 \pm 0.21^{\mathrm{a}}$ & $1.1 \pm 0.2^{\mathrm{a}}$ & $1.15 \pm 0.28^{\mathrm{a}}$ \\
\hline C20:5n-3 & $1.18 \pm 0.21^{\mathrm{a}}$ & $1.01 \pm 0.19^{\mathrm{a}}$ & $0.94 \pm 0.22^{\mathrm{a}}$ \\
\hline$C 22: 5 n-3$ & $0.71 \pm 0.1^{\mathrm{a}}$ & $0.87 \pm 0.11^{\mathrm{a}}$ & $0.92 \pm 0.09^{b}$ \\
\hline C22:6n-3 & $11.25 \pm 1.21^{\mathrm{b}}$ & $12.34 \pm 1.43^{\mathrm{a}, \mathrm{b}}$ & $13.1 \pm 0.88^{\mathrm{a}}$ \\
\hline Total n-3 PUFA & $14.17 \pm 1.34^{\mathrm{a}}$ & $15.31 \pm 1.35^{\mathrm{a}, \mathrm{b}}$ & $16.12 \pm 0.96^{\mathrm{b}}$ \\
\hline Ximenynic acid & nd & $0.6 \pm 0.19^{\mathrm{b}}$ & $0.85 \pm 0.22^{\mathrm{a}}$ \\
\hline$n-6 / n-3$ & $2.56 \pm 0.19^{\mathrm{b}}$ & $2.33 \pm 0.19^{\mathrm{a}}$ & $2.2 \pm 0.17^{\mathrm{a}}$ \\
\hline
\end{tabular}

Values represent mean $\% \pm$ SD. $n=10$. For each fatty acid, values sharing the same superscript letter indicate no significant difference, as determined by one-way analysis of variance $(p<$ $0.05)$. nd, not detected; SWSO, sandalwood seed oil; OO, olive oil; $\mathrm{SO}, \mathrm{SWSO}+\mathrm{OO}$.

the livers of mice in the SWSO group had significantly higher levels of C16:1n-7 ( $p<0.05)$, but lower levels of C18:1n-9 $(p<0.05)$, total n-9 monounsaturated fatty acids (MUFA) $(p<0.05)$ and total MUFA $(p<0.05)$ compared to the OO group. Other MUFA, such as C20:1n-9, C22:1n-9, and C24:1n-9, were not different between the SWSO and the OO group.

For PUFA, C20:2n-6 and C20:3n-6 were significantly higher in the SWSO group than the OO group $(p<0.05)$, while C22:4n-6 was markedly lower. There were no significant differences in total n-6 PUFA between any of the experimental groups. 
While C18:3n-3 and C20:5n-3 were similar between the SWSO group and the OO group, levels of C22:5n-3, C22:6n-3, and total n-3 PUFA were significantly higher compared to the OO group $(p<0.05)$. The $n-6: n-3$ ratio was lower in the SWSO group than the OO group. It is possible that the n-3 PUFA level was in response to the concentration of SWSO after feeding mice (Table 4).

\section{Effects of SWSO on Mouse Brain Fatty Acid}

\section{Composition}

The fatty acid composition of mouse brain was not the same as that observed in hepatic tissue following the experimental treatments (Table 5). Compared to the $\mathrm{OO}$ and the $\mathrm{SO}$ group, there were no significant differences in the SWSO group in most SFA and MUFA, total n-9 MUFA, and total MUFA. C20:3n-6 was significantly higher in the SWSO group than the OO group $(p<0.05)$, but there was no significant difference in most $n-6$ PUFA and total n-6 PUFA levels between the SWSO and the OO group. C22:5n-3 was significantly higher in the SWSO group than the OO group $(p<0.05)$. Total $n-3$ PUFA in the SWSO group was markedly lower than in the $\mathrm{OO}$ and the SO group $(p<0.05)$, and the n-6:n-3 ratio was higher than in the OO group.

\section{Free Fatty Acid Uptake by HepG2 Cells}

It has previously been reported that ximenynic acid can be taken up by the liver (and many other tissues) of mice and rats $[7,8]$, but little is known about its uptake in human tissue. HepG2 cells were treated with oleic acid or ximenynic acid for $48 \mathrm{~h}$ at different concentrations (ranging from 0 to $150 \mu \mathrm{M}$ ) in fatty acid-free conditions. As shown in Figure 1, the number of intracellular lipid droplets increased in accordance with fatty acid concentration compared to the vehicle, especially in ximenynic acidtreated cells. This suggests that ximenynic acid was taken up by HepG 2 cells and may regulate triglyceride synthesis in human liver cells.

\section{Effects of Ximenynic Acid on HepG2 Fatty Acid Composition}

After a 48-h incubation with either ximenynic acid or oleic acid, the lipid composition of HepG2 cells was analyzed by gas chromatography (Table 6). As expected, the relative levels of cellular ximenynic acid and oleic acid increased in accordance with increasing concentrations. Compared to the vehicle, C14:0, C16:0, C18:0, and total SFA levels were significantly reduced with increasing concentrations of both ximenynic acid and oleic acid $(p<0.05)$. C18:1n-9, C20:1n-9, total n-9 MUFA, and total
Table 5. Effects of different oil feeds on total fatty acid composition in mouse brain

\begin{tabular}{|c|c|c|c|}
\hline Fatty acids & $\mathrm{OO}$ & SO & SWSO \\
\hline C14:0 & $0.15 \pm 0.04^{\mathrm{a}}$ & $0.11 \pm 0.03^{\mathrm{a}}$ & $0.11 \pm 0.02^{\mathrm{a}}$ \\
\hline C15:0 & $0.07 \pm 0.02^{\mathrm{b}}$ & $0.05 \pm 0.01^{\mathrm{ab}}$ & $0.04 \pm 0.03^{\mathrm{a}}$ \\
\hline $\mathrm{C} 16: 0$ & $17 \pm 1.15^{\mathrm{a}}$ & $16.53 \pm 1.47^{\mathrm{a}}$ & $17.24 \pm 1.69^{a}$ \\
\hline $\mathrm{C} 17: 0$ & $0.14 \pm 0.02^{\mathrm{a}}$ & $0.12 \pm 0.02^{\mathrm{a}}$ & $0.13 \pm 0.01^{\mathrm{a}}$ \\
\hline C18:0 & $16.98 \pm 0.95^{\mathrm{a}}$ & $16.42 \pm 1.07^{\mathrm{a}}$ & $17.83 \pm 1.52^{\mathrm{a}}$ \\
\hline C20:0 & $0.38 \pm 0.16^{\mathrm{a}}$ & $0.34 \pm 0.16^{\mathrm{a}}$ & $0.42 \pm 0.17^{\mathrm{a}}$ \\
\hline $\mathrm{C} 22: 0$ & $0.41 \pm 0.16^{\mathrm{a}}$ & $0.41 \pm 0.24^{\mathrm{a}}$ & $0.43 \pm 0.12^{\mathrm{a}}$ \\
\hline $\mathrm{C} 24: 0$ & $0.7 \pm 0.3^{\mathrm{a}}$ & $0.56 \pm 0.22^{\mathrm{a}}$ & $0.76 \pm 0.25^{\mathrm{a}}$ \\
\hline Total SFA & $35.82 \pm 1.59^{\mathrm{a}}$ & $34.54 \pm 2.16^{\mathrm{a}}$ & $36.96 \pm 2.87^{a}$ \\
\hline C16:1n-7 & $0.48 \pm 0.05^{\mathrm{a}}$ & $0.52 \pm 0.04^{\mathrm{a}}$ & $0.51 \pm 0.08^{\mathrm{a}}$ \\
\hline C17:1n-7 & $3.19 \pm 0.32^{\mathrm{a}}$ & $3.42 \pm 0.54^{\mathrm{a}}$ & $3.2 \pm 0.34^{\mathrm{a}}$ \\
\hline C18:1n-9 & $18.7 \pm 2.48^{\mathrm{a}}$ & $17.98 \pm 2.91^{\mathrm{a}}$ & $18.92 \pm 2.02^{\mathrm{a}}$ \\
\hline C20:1n-9 & $2.23 \pm 0.95^{\mathrm{a}}$ & $2.1 \pm 1.13^{\mathrm{a}}$ & $2.23 \pm 0.79^{\mathrm{a}}$ \\
\hline C22:1n-9 & $2.13 \pm 0.56^{\mathrm{a}}$ & $1.97 \pm 0.63^{\mathrm{a}}$ & $2.27 \pm 0.68^{\mathrm{a}}$ \\
\hline C24:1n-9 & $1.95 \pm 0.81^{\mathrm{a}}$ & $1.87 \pm 0.8^{\mathrm{a}}$ & $2.28 \pm 0.72^{\mathrm{a}}$ \\
\hline Total n-9 MUFA & $25.02 \pm 4.63^{\mathrm{a}}$ & $23.93 \pm 4.77^{\mathrm{a}}$ & $25.7 \pm 3.21^{\mathrm{a}}$ \\
\hline Total MUFA & $28.69 \pm 4.67^{\mathrm{a}}$ & $27.86 \pm 4.99^{\mathrm{a}}$ & $29.4 \pm 3.39^{a}$ \\
\hline C18:2n-6 & $0.95 \pm 0.09^{\mathrm{a}}$ & $0.82 \pm 0.08^{\mathrm{a}}$ & $0.93 \pm 0.34^{\mathrm{a}}$ \\
\hline$C 20: 2 n-6$ & $0.24 \pm 0.11^{\mathrm{a}}$ & $0.24 \pm 0.11^{\mathrm{a}}$ & $0.2 \pm 0.08^{\mathrm{a}}$ \\
\hline$C 20: 3 n-6$ & $0.55 \pm 0.04^{\mathrm{a}}$ & $0.62 \pm 0.05^{\mathrm{b}}$ & $0.63 \pm 0.04^{\mathrm{b}}$ \\
\hline$C 20: 4 n-6$ & $10.2 \pm 2.09^{\mathrm{a}}$ & $10.65 \pm 2.3^{\mathrm{a}}$ & $9.58 \pm 1.21^{\mathrm{a}}$ \\
\hline$C 22: 4 n-6$ & $2.55 \pm 0.27^{\mathrm{a}}$ & $2.65 \pm 0.42^{\mathrm{a}}$ & $2.43 \pm 0.23^{\mathrm{a}}$ \\
\hline Total n-6 PUFA & $14.49 \pm 2.17^{\mathrm{a}}$ & $14.98 \pm 2.53^{\mathrm{a}}$ & $13.77 \pm 1.18^{\mathrm{a}}$ \\
\hline$C 20: 5 n-3$ & $0.11 \pm 0.06^{\mathrm{a}}$ & $0.14 \pm 0.1^{\mathrm{a}}$ & $0.19 \pm 0.15^{\mathrm{a}}$ \\
\hline$C 22: 5 n-3$ & $0.2 \pm 0.02^{\mathrm{a}}$ & $0.27 \pm 0.05^{\mathrm{b}}$ & $0.27 \pm 0.04^{\mathrm{b}}$ \\
\hline$C 22: 6 n-3$ & $20.13 \pm 1.77^{\mathrm{a}}$ & $21.98 \pm 2.29^{\mathrm{b}}$ & $19.11 \pm 1.03^{\mathrm{a}}$ \\
\hline Total n-3 PUFA & $23 \pm 1.95^{\mathrm{b}}$ & $22.39 \pm 2.31^{\mathrm{b}}$ & $19.57 \pm 0.95^{\mathrm{a}}$ \\
\hline Ximenynic acid & nd & $0.13 \pm 0.04^{\mathrm{a}}$ & $0.19 \pm 0.05^{\mathrm{b}}$ \\
\hline$n-6 / n-3$ & $0.63 \pm 0.05^{\mathrm{a}}$ & $0.67 \pm 0.06^{\mathrm{a}, \mathrm{b}}$ & $0.70 \pm 0.05^{\mathrm{b}}$ \\
\hline
\end{tabular}

Values represent mean $\% \pm$ SD. $n=10$. For each fatty acid, values sharing the same superscript letter indicate no significant difference (one-way analysis of variance) $(p<0.05)$. nd, not detected; SWSO, sandalwood seed oil; OO, olive oil; SO, SWSO + OO.

MUFA levels were reduced by ximenynic acid in a dosedependent manner $(p<0.05)$ compared to the vehicle and oleic acid groups. In contrast, C20:1n-9, total n-9 MUFA, and total MUFA levels were markedly increased with oleic acid treatment compared to the vehicle $(p<0.05)$.

C18:2n-6, C20:4n-6, and total n-6 PUFA were significantly reduced with ximenynic acid and oleic acid compared to the vehicle in a dose-dependent manner $(p<$ $0.05)$. However, there were no differences in these fatty acids when comparing cells treated with ximenynic acid or oleic acid at $150 \mu \mathrm{M}$.

Although the level of C22:5n-3, C22:6n-3, and total n-3 PUFA did not change compared with oleic acid and
68

Lifestyle Genomics 2020;13:64-73 DOI: $10.1159 / 000502773$
Cai/Liu/Hettiarachichi/Wang/Li/ Sunderland/Li 


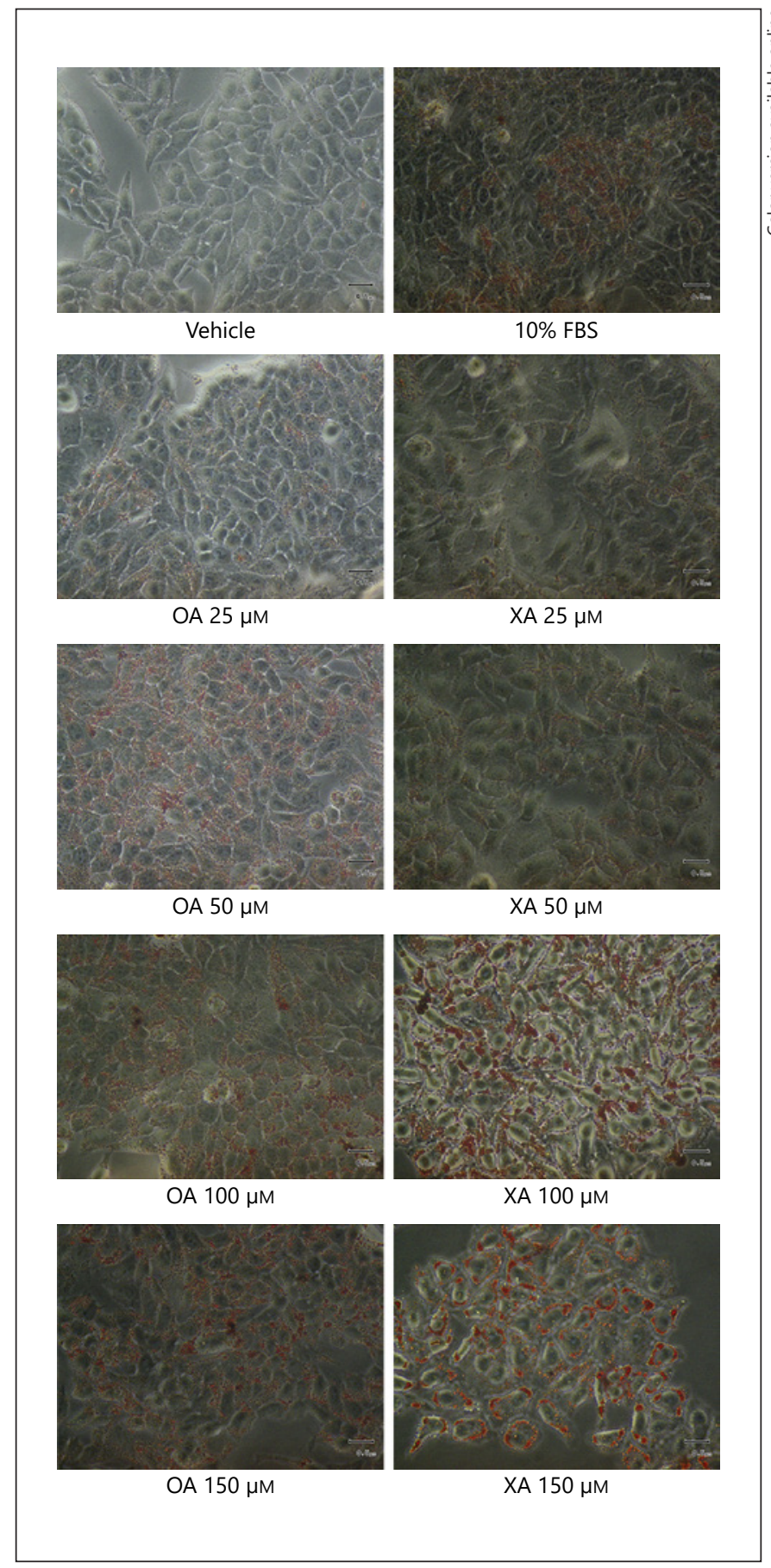

Fig. 1. Oil-red-O staining of HepG2 cells after fatty acid treatment. OA, oleic acid; XA, ximenynic acid. $\times 400$. ximenynic acid treatment $(150 \mu \mathrm{M})$, these fatty acids were significantly lower compared to vehicle treatment $(p<$ 0.05).

Effects of Ximenynic Acid on HepG2 Gene Expression

FADS1 $\left(\Delta^{5}\right.$ desaturase $)$ and FADS2 $\left(\Delta^{6}\right.$ desaturase $)$ are key rating-limiting enzymes for the synthesis of longchain n-3 PUFA. Stearoyl-CoA desaturase (SCD, $\Delta^{9}$ desaturase) is the rate-limiting enzyme that catalyzes MUFA synthesis. To analyze the effects of ximenynic acid on fatty acid synthesis pathways in HepG2 cells, we examined the expression of 6 key genes by quantitative PCR. The results showed that treating HepG2 cells for $72 \mathrm{~h}$ with $150 \mu \mathrm{M}$ ximenynic acid significantly inhibited the expression of SCD and FADS2 compared to the vehicle $(p<0.05)$ but did not affect the expression of ELOVL2, ELOVL5, ELOVL6, or FADS1 (Fig. 2). Interestingly, oleic acid dramatically suppressed the expression of both SCD and FADS1 compared to the vehicle $(p<$ 0.05) (Fig. 2).

We also extracted total cellular protein and analyzed FADS2 protein expression by Western blotting. The results showed that the expression of FADS2 protein was also influenced by ximenynic acid in a dose-dependent manner, while oleic acid had no effect (Fig. 3).

\section{Discussion/Conclusion}

Ximenynic acid is a rare fatty acid that is abundant in SWSO; however, its effect on fatty acid metabolism is poorly studied. Therefore, the current study aimed to examine the effects of both SWSO and ximenynic acid on n-3 fatty acid metabolism in both mouse and human liver cells (Fig. 4). The major components of SWSO are oleic acid and ximenynic acid; therefore, using $\mathrm{OO}$ (which contains $\sim 80 \%$ oleic acid) as a control is ideal for determining the effects of ximenynic acid on fatty acid metabolism in mice. Our results show that SWSO significantly elevated the levels of total n-3 PUFA and decreased total n-9 MUFA in the mouse liver compared to mice treated with OO. Interestingly, total $n-3$ PUFA in the mouse brain was significantly reduced $(p<0.05)$. To investigate these effects further, we performed an in vitro study using HepG2 liver cells.

The liver is an essential organ for fatty acid metabolism and is sensitive to changes in dietary lipid content [23]. Compared with the $\mathrm{OO}$ control group, mice treated with SWSO had lower total n-9 MUFA and higher n-3 PUFA, especially C22:6n-3. This difference may be explained by 
Table 6. Effects of ximenynic acid on total fatty acid composition of HepG2 cells

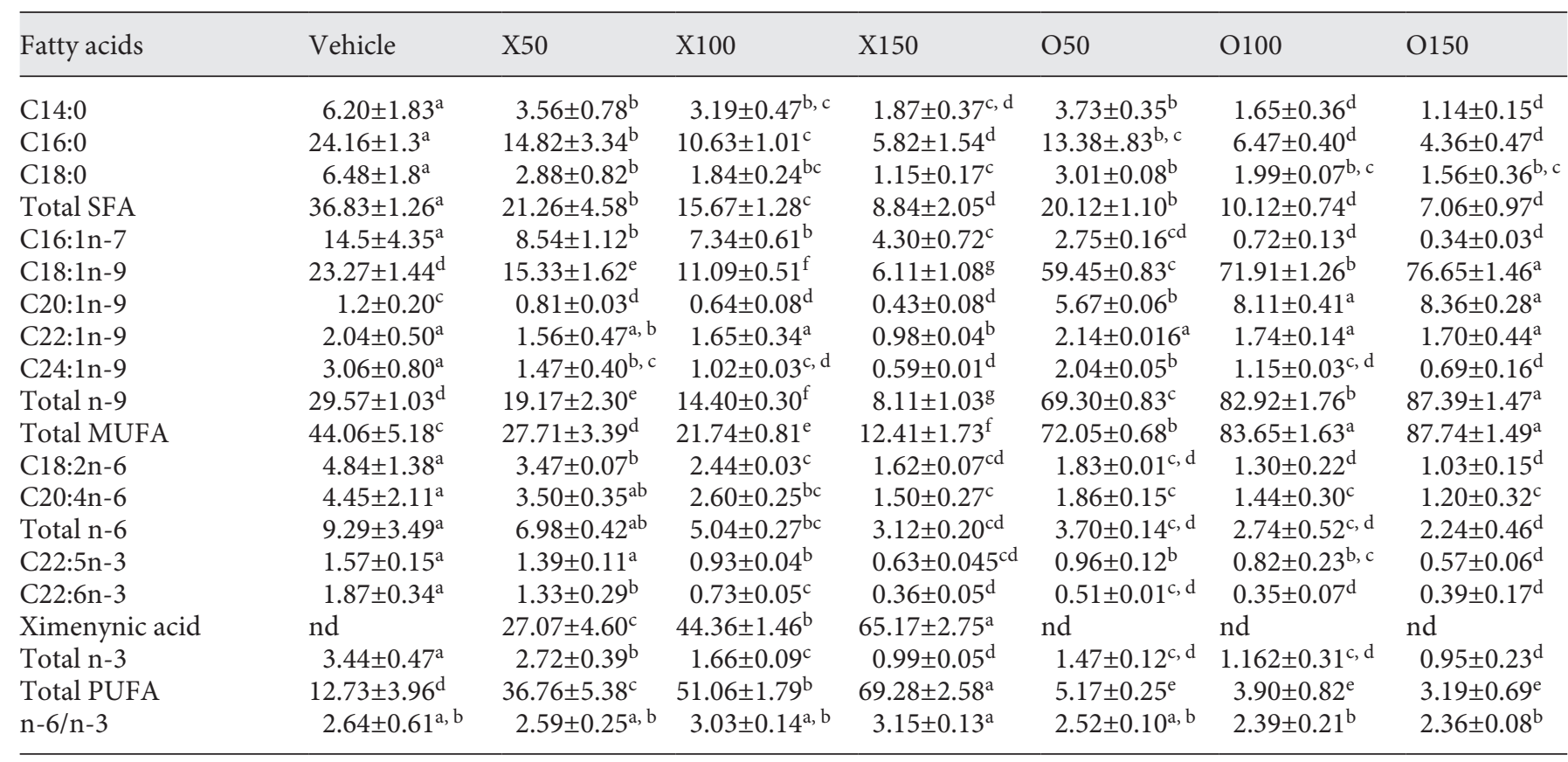

Values are mean $\% \pm \mathrm{SD}(n=3)$. For each fatty acid, values sharing the same superscript letter indicate no significant difference, as determined by one-way analysis of variance $(p<0.05)$. nd, not detected; X, ximenynic acid; O, oleic acid.

the fact that ximenynic acid can impact n-9 MUFA synthesis directly or that the oleic acid levels in $\mathrm{OO}$ were higher than in SWSO. The higher content of C22:6n-3 and n-3 PUFA may be due to the ability of SWSO to activate n-3 PUFA synthesis enzymes or simply related to the fact that $\mathrm{C} 18: 3 \mathrm{n}-3$ levels (a C22:6n-3 precursor) are higher in SWSO than OO.

n-3 fatty acids are essential for brain development and function from infants to elderly adults. A previous study reported that mice fed SWSO showed no detectable levels of ximenynic acid in the brain [10]. The present study indicated that SWSO may have positive effects on n-3 PUFA levels in the mouse liver compared with OO, but the levels of these same fatty acids are down-regulated in the brain. In HepG2 cells, C22:6n-3 was significantly decreased, while SCD, FADS1, and FADS2 gene expression, as well as FADS2 protein expression, was significantly down-regulated following a 72-h incubation with $150 \mu \mathrm{M}$ of ximenynic acid compared with vehicle. Further, we found ximenynic acid to be present at very low levels in the mouse brain following gavage with SWSO and SO, indicating that ximenynic acid can penetrate the blood-brain barrier and enter brain tissue, which might inhibit the formation of n-3 fatty acids. However, these low levels probably have little influence on the overall fatty acid concentration in the mouse brain. In contrast, our results may suggest that ximenynic acid might prevent the brain from obtaining n-3 PUFA critical for brain development.

FADS1 and FADS2 are key enzymes for endogenous PUFA synthesis, and they encode $\Delta^{5}$ and $\Delta^{6}$ desaturase in humans, respectively [24]. C22:6n-3 concentration was markedly lower in HepG2 cells following ximenynic acid treatment compared to oleic acid treatment, and FADS2 expression was also reduced. Moreover, FADS2 protein expression corroborated FADS2 gene expression results. Compared with oleic acid groups, total n-3 PUFA levels in ximenynic acid-treated cells were not affected by different concentrations. It might be because oleic acid also has a negative effect on n-3 fatty acid metabolism through FADS1 inhibition. The present study is consistent with a previous study [10] that showed that SWSO had a progressive effect on C22:6n-3 levels in the mouse liver. However, our in vitro study did not support that ximenynic acid could enhance n-3 PUFA synthesis. Therefore, the increased levels of n-3 PUFA in the mouse liver might be due to other factors. 


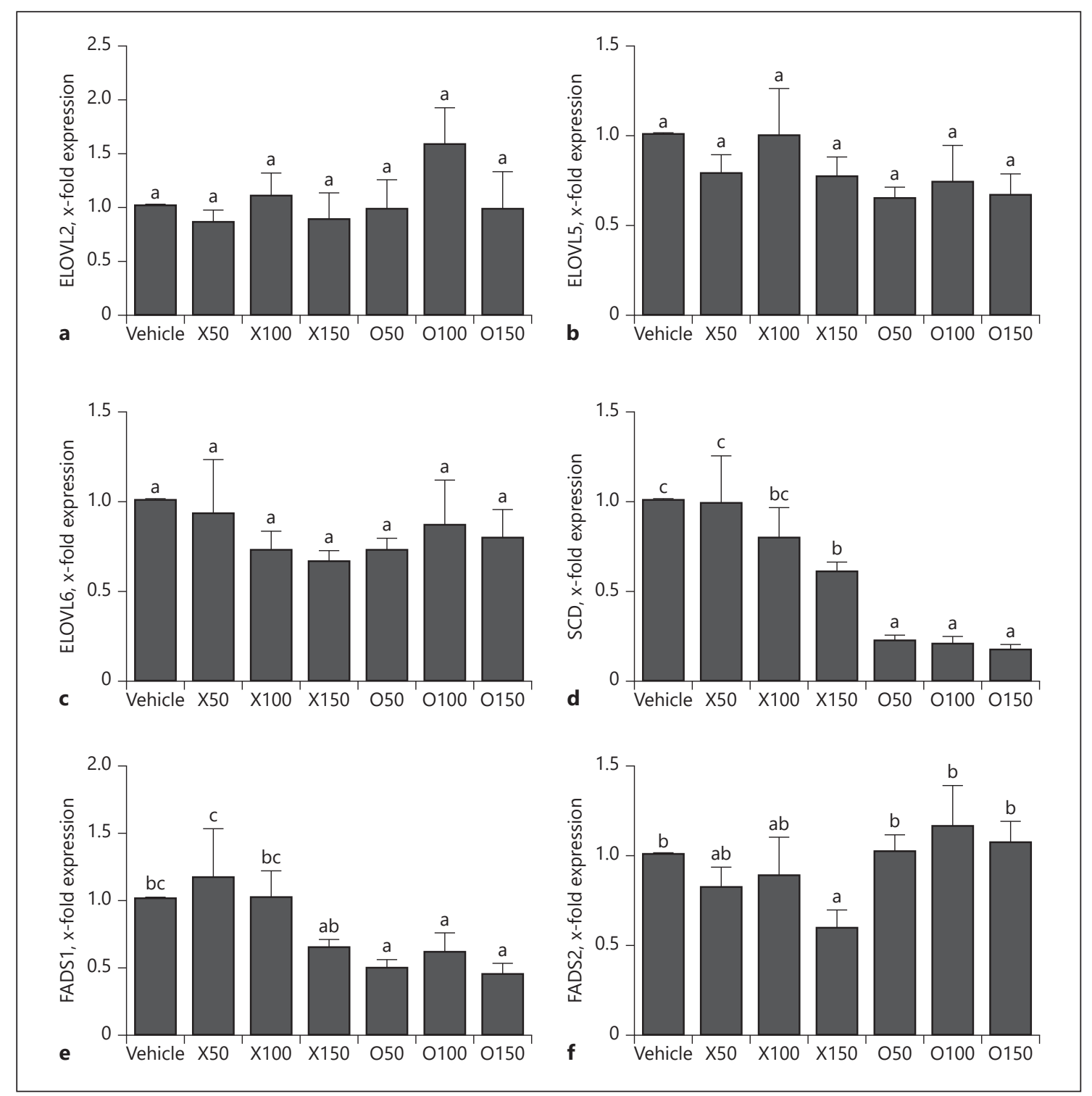

Fig. 2. a-f Expression of genes involved in fatty acid metabolism in HepG2 cells. Data were obtained from 3 different passages, and each passage was run in triplicate. Results are presented as means \pm SD ( $n=3$ different passages). Bars sharing the same superscript letters are not significantly different $(p<0.05)$ from one another, as determined by one-way analysis of variance. $\mathrm{X}$, ximenynic acid; O, oleic acid; vehicle, DMSO + BSA.

SCD is a crucial enzyme for the synthesis of MUFA from SFA. This enzyme especially catalyzes the dehydrogenation of SFA at the $\Delta^{9}$ position [25]. Therefore, a reduction in SCD activity generally corresponds to a decrease in MUFA synthesis. The present in vitro study shows for the first time that n-9 MUFA, e.g., C18:1n-9, C20:1n-9, and C24:1n-9, were markedly and dose-dependent reduced by ximenynic acid. We also found that high treatment levels of ximenynic acid significantly sup- pressed $S C D$ gene expression. Together, this suggests that ximenynic acid may be involved in the regulation of $n-9$ MUFA synthesis. The similar structure between ximenynic acid and oleic acid may explain why SCD was inhibited.

In conclusion, ximenynic acid might affect $n-3$ PUFA metabolism by regulating the expression of key enzymes in the liver, such as FADS2. However, oleic acid might be in a position to suppress the expression 


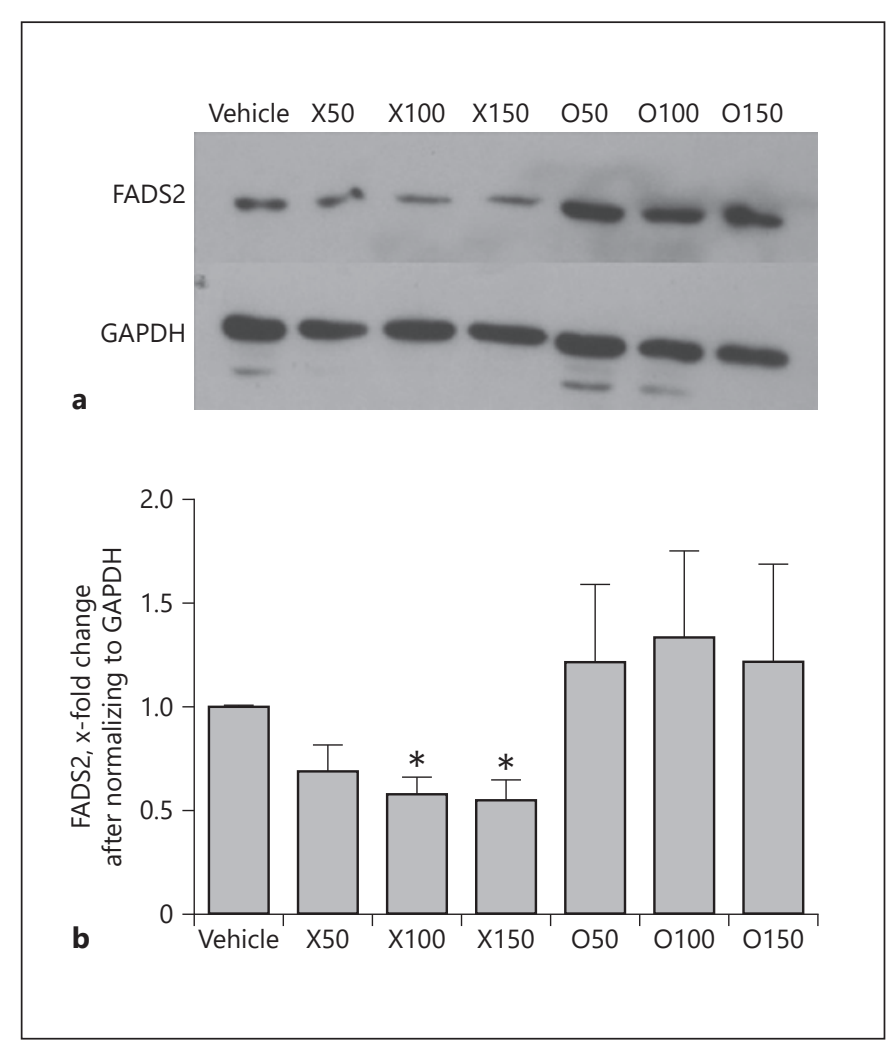

Fig. 3. a, b Effect of fatty acid treatment on FADS2 protein expression in HepG2 cells. Results are presented as means \pm SD $(n=3)$. $* p<0.05$ vs. the vehicle group (DMSO + BSA) (independentsample $t$ tests). $\mathrm{X}$, ximenynic acid; $\mathrm{O}$, oleic acid.

of $\Delta^{5}$ desaturase FADS1 in HepG2 cells. SWSO has a positive impact on n-3 PUFA levels in the mouse liver but a negative one in the mouse brain. The different effects of SWSO on n-3 PUFA levels in the mouse brain and liver might be because the basic feed consumed by mice provided sufficient $\mathrm{C} 18: 3 \mathrm{n}-3$ to support brain development. Therefore, the gavage experimental oils may have been completely metabolized by the liver. Although our in vitro study showed that ximenynic acid inhibited FADS2 expression in HepG2 cells, our results suggest that the high levels of C18:3n-3 in SWSO might overcome this ximenynic acid inhibition in vivo and promote the endogenous production of C22:6n-3 in the mouse liver.

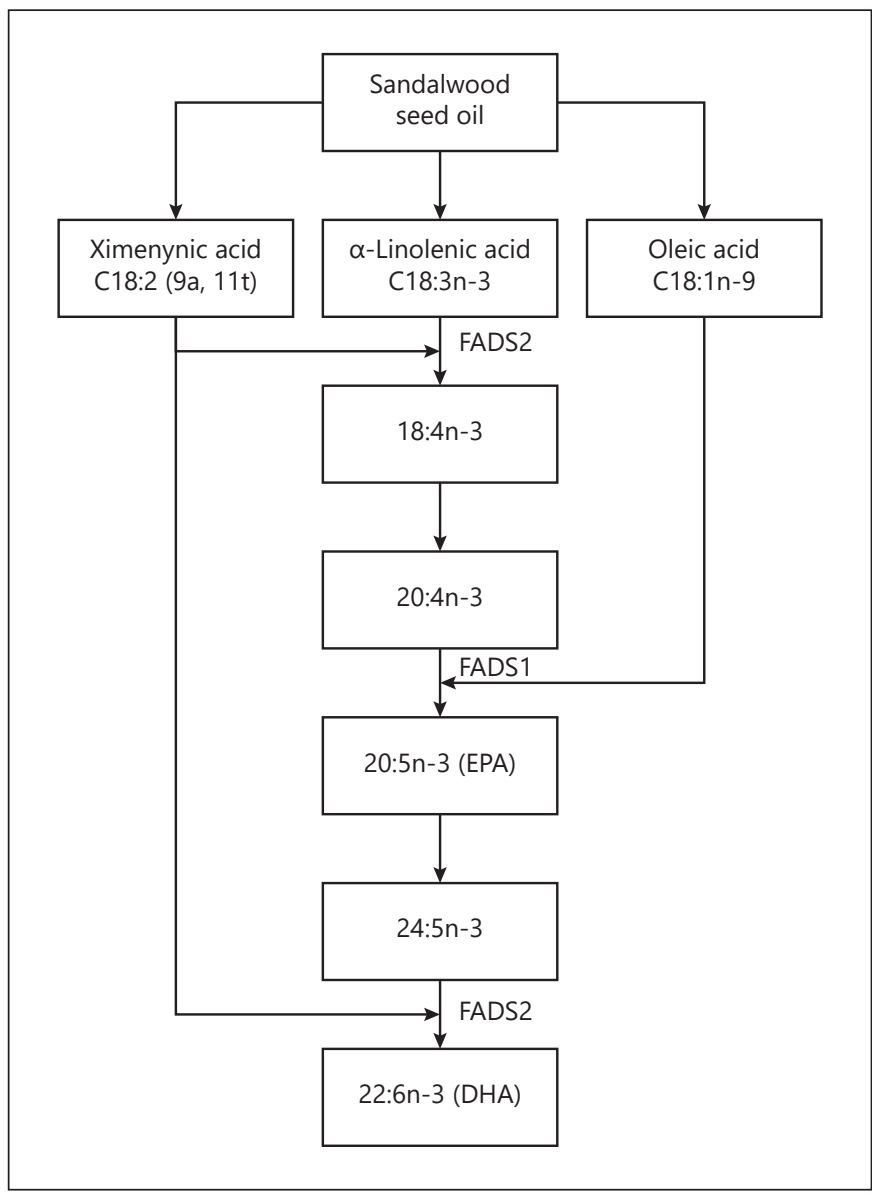

Fig. 4. Proposed effect of sandalwood seed oil on n-3 fatty acid metabolism pathways.

\section{Acknowledgment}

This work was supported by the National Basic Research Program of China (973 Program: 2015CB553604); by the National Natural Science Foundation of China (NSFC: 81773433); and by the Key Scientific Research Projects in Shandong Provence, China (2017YYSP007).

\section{Statement of Ethics}

This work was approved by the Ethics Committee of the College of Biosystems Engineering and Food Science, Zhejiang University.

\section{Disclosure Statement}

The authors have no conflicts of interest to report in respect of this work. 


\section{References}

1 Aitzetmüller K. Santalbic acid in the plant kingdom. Plant Syst Evol. 2012 Nov;298(9): 1609-17.

2 Jones GP, Birkett A, Sanigorski A, Sinclair AJ, Hooper PT, Watson T, et al. Effect of feeding quandong (Santalum acuminatum) oil to rats on tissue lipids, hepatic cytochrome P-450 and tissue histology. Food Chem Toxicol. 1994 Jun;32(6):521-5.

3 Rezanka T, Sigler K. Identification of very long chain unsaturated fatty acids from Ximenia oil by atmospheric pressure chemical ionization liquid chromatography-mass spectroscopy. Phytochemistry. 2007 Mar;68(6): 925-34.

4 Liu YD, Longmore RB. A biotransformation product of ximenynic acid and its significance. Proc Nutr Soc Aus. 1996:20;182.

5 Liu YD, Longmore RB, Fox JE. Separation and identification of ximenynic acid isomers in the seed oil of Santalum spicatum $\mathrm{RBr}$ as their 4,4-dimethyloxazoline derivatives. J Am Oil Chem Soc. 1996 Dec;73(12):1729-31.

6 Nugteren DH, Christ-Hazelhof E. Naturally occurring conjugated octadecatrienoic acids are strong inhibitors of prostaglandin biosynthesis. Prostaglandins. 1987 Mar;33(3):403-17.

7 Croft KD, Beilin LJ, Ford GL. Differential inhibition of thromboxane B2 and leukotriene B4 biosynthesis by two naturally occurring acetylenic fatty acids. Biochim Biophys Acta. 1987 Oct;921(3):621-4.

8 Cai F, Li J, Liu Y, Zhang Z, Hettiarachchi DS, Li D. Effect of ximenynic acid on cell cycle arrest and apoptosis and COX-1 in HepG2 cells. Mol Med Rep. 2016 Dec;14(6):5667-76.

9 Jones GP, Rao KS, Tucker DJ, Richardson B, Barnes A, Rivett DE. Antimicrobial activity of santalbic acid from the oil of Santalum acumi- natum (Quandong). Int J Pharmacogn. 1995 Jun;33(2):120-3.

10 Liu Y, Longmore RB. Dietary sandalwood seed oil modifies fatty acid composition of mouse adipose tissue, brain, and liver. Lipids. 1997 Sep;32(9):965-9.

11 Li G, Singh A, Liu Y, Sunderland B, Li D. Comparative effects of sandalwood seed oil on fatty acid profiles and inflammatory factors in rats. Lipids. 2013 Feb;48(2):105-13.

12 Saini RK, Keum YS. Omega-3 and omega-6 polyunsaturated fatty acids: Dietary sources, metabolism, and significance - A review. Life Sci. 2018 Jun;203:255-67.

13 Uauy R, Hoffman DR, Peirano P, Birch DG, Birch EE. Essential fatty acids in visual and brain development. Lipids. 2001 Sep;36(9): 885-95.

14 Nakamura MT, Nara TY. Structure, function, and dietary regulation of delta6, delta5, and delta9 desaturases. Annu Rev Nutr. 2004. 24(1):345-76

15 Stoffel W, Holz B, Jenke B, Binczek E, Günter $\mathrm{RH}$, Kiss C, et al. Delta6-desaturase (FADS2) deficiency unveils the role of omega3- and omega6-polyunsaturated fatty acids. EMBO J. 2008 Sep;27(17):2281-92.

16 Siscovick DS, Barringer TA, Fretts AM, Wu $\mathrm{JH}$, Lichtenstein $\mathrm{AH}$, Costello $\mathrm{RB}$, et al.; American Heart Association Nutrition Committee of the Council on Lifestyle and Cardiometabolic Health; Council on Epidemiology and Prevention; Council on Cardiovascular Disease in the Young; Council on Cardiovascular and Stroke Nursing; and Council on Clinical Cardiology. Omega-3 Polyunsaturated Fatty Acid (Fish Oil) Supplementation and the Prevention of Clinical Cardiovascular Disease: A Science Advisory From the Amer- ican Heart Association. Circulation. 2017 Apr;135(15):e867-84.

17 Zheng JS, Lin M, Fang L, Yu Y, Yuan L, Jin Y, et al. Effects of n-3 fatty acid supplements on glycemic traits in Chinese type 2 diabetic patients: A double-blind randomized controlled trial. Mol Nutr Food Res. 2016 Oct;60(10): 2176-84.

18 Zheng JS, Lin M, Imamura F, Cai W, Wang L, Feng JP, et al. Serum metabolomics profiles in response to $\mathrm{n}-3$ fatty acids in Chinese patients with type 2 diabetes: a double-blind randomised controlled trial. Sci Rep. 2016 Jul; 6(1):29522.

19 Fabian CJ, Kimler BF, Hursting SD. Omega-3 fatty acids for breast cancer prevention and survivorship. Breast Cancer Res. 2015 May; 17(1):62.

20 Dyall SC. Long-chain omega- 3 fatty acids and the brain: a review of the independent and shared effects of EPA, DPA and DHA. Front Aging Neurosci. 2015 Apr;7:52.

21 Calder PC. Omega-3 fatty acids and inflammatory processes: from molecules to man. Biochem Soc Trans. 2017 Oct;45(5):1105-15.

22 Hettiarachchi D, Liu Y, Fox J, Sunderland B. Western Australian sandalwood seed oil: new opportunities. Lipid Technol. 2010;22(2): 27-9.

23 Rui L. Energy metabolism in the liver. Compr Physiol. 2014 Jan;4(1):177-97.

24 Glaser C, Heinrich J, Koletzko B. Role of FADS1 and FADS2 polymorphisms in polyunsaturated fatty acid metabolism. Metabolism. 2010 Jul;59(7):993-9.

25 Ntambi JM. Regulation of stearoyl-CoA desaturase by polyunsaturated fatty acids and cholesterol. J Lipid Res. 1999 Sep;40(9):1549_ 58. 